\title{
Learning achievement goal theory and teaching students legal problem solving
}

Dr Hazel Dawe, Teaching Fellow, Oxford Brookes University.

Correspondence address: Oxford Brookes, Law School, Gipsy Lane Oxford, OX3 OPB

key terms: scaffolding instruction, legal problem solving, $2 \times 2$ achievement goal theory

"This article has been accepted for publication in The Law Teacher, published by Taylor \& Francis."

\section{Abstract}

This article examines achievement goal theory and how it describes student approaches to learning. It adopts the $2 \times 2$ achievement goal framework and examines how mastery goal achievement orientation in students fosters better quality, deep learning and leads to better outcomes. It then explores how a mastery goal achievement approach in students can be encouraged through the use of scaffolding instruction. It looks at the use of scaffolding instruction in two particular contexts: creating a supportive classroom social environment and setting classroom and assessment tasks which are appropriately challenging in the context of setting legal problem questions. It examines the empirical evidence that encouraging mastery goal achievement approaches in students using these two methods can improve their deep learning and also their results. It also gives examples of the author's own experience of using scaffolding instruction to improve students results, in particular as regards teaching legal problem solving to business school students with no prior knowledge of the law or legal problem solving.

\section{Article}

The expansion of higher education has changed the nature of the student body and led to a need to review the pedagogy used in universities. As student numbers have increased and funding per student has decreased, class sizes have crept up from the six to eight of thirty odd years ago to the 
fifteen to twenty five of today. ${ }^{1}$ The intimate conversation of a group of six to eight is not suited to a class of twenty five and tutors have had to adapt the pedagogy they use to acknowledge this difference. Simultaneously, the expansion of higher education has led to an increase in the numbers and proportion of what is know as atypical students. ${ }^{2}$ These students often lack the self-confidence of the typical student. They may also lack many of the academic skills which would previously have been taken for granted in new students. This article therefore reviews how students learn using learning achievement theory in order to inform the pedagogy of teaching and learning in today's higher education environment. It does so by interrogating the link between student motivation and student achievement. It starts by examining the subdivision of student motivation into mastery goal theory and performance goal theory and what these tell us about how students learn. It then discusses the subdivision of these two categories into achievement strategy and avoidance strategy to create a new more refined $2 \times 2$ structure.

How lecturers can encourage deep learning by influencing student motivation is explored through the prism of scaffolding instruction with examples which have been used by the author in both teaching and assessment. This explains how giving students more support at the start of their studies when they encounter novel assessments can enhance their self confidence and their mastery of the requisite skills. The 'scaffolding' is then removed leaving them to become competent and self confident learners.

\section{Learning Achievement theory}

Learning achievement theory describes how students are motivated to learn and how different types of motivation produce different outcomes. Learning is influenced by 'individual's perceptions of their

1 Orlana Bandiera, Valentino Larcinese and Imran Rasul, Heterogenous class size effects: new evidence from a panel of university students, The Economic Journal, 120 (December) 13675 - 1398, 2010

2 Digby Warren, Curriculum Design in a Context of Widening Participation in Higher Education, Arts and Humanities in Higher Education Vol 1(1) 85-89, 20023 
own competence, perceptions of the difficulty of different tasks and their individual goals. ${ }^{3}$

Students' approach to learning achievement can be described by two different theories: mastery goal theory and performance goal theory.

\subsection{Mastery goal theory:}

Mastery goal, or task involvement, oriented students are motivated to develop new skills, try to understand their work and improve their level of competence. These are all elements of learning which are likely to improve the quality of their learning and help them develop deep learning skills. ${ }^{4}$ There is a 'generally positive constellation with mastery goals...students generally persist longer when faced with difficulty, are more willing to attempt difficult or challenging tasks and use more deep level cognitive processing strategies, are more intrinsically motivated and feel better about [their] work. ${ }^{5}$ They are more likely to 'choose challenging tasks and are more concerned with their own progress than with outperforming others. ${ }^{6}$ If students believe that effort will be rewarded by better outcomes this motivates them to work at learning.

The efficacy of mastery goal theory has been confirmed by a meta study by Rocca on student participation which drew together journal articles published over a period of 51 years (1958-2009) from five key journals on instructional communication studies ${ }^{7}$ The study created an extensive literature review which demonstrates that active participation in the class helps students to learn better and think critically: student grades also improve as their participation increases. ${ }^{8}$

\footnotetext{
${ }^{3}$ Jacquelynne Eccles and Allan Wigfield, Schooling's Influences on Motivation and Achievement, Chapter 5 in Securing the Future in Children from Birth to College, S Danziger and J Walkvogel, New York, Russell Sage Foundations , 2000, pp. $167-169$, p.154

${ }^{4}$ Carole Ames, Classrooms; Goals, Structures, and Student Motivation, Journal of Educational Psychology, 1992, Vol 84, No $3261-271$, p262

${ }^{5}$ Tim Urdan and Erin Schoenfelder, Classroom effects on student motivation: Goal structures, social relationships, and competence beliefs, Journal of School Psychology, Vol 44, (2006)331 - 349, p 334

${ }^{6}$ Eccles and Wigfield, p.158

${ }^{7}$ The five journals are: Communication Education, Speech Teacher, Communication Research reports, Communication Quarterly, Communication Yearbook.

${ }^{8}$ Kelly A Rocca, Student Participation in the College Classroom: An Extended Multidisciplinary Literature Review, Communication Education Vol 59, No 2, April 2010 pp 185 - 213
} 
Mastery goal theory sees a role for teachers in developing student approaches to learning which can help atypical students in particular, but also first year students transitioning from the school system to university, to enhance the efficacy of their learning. It postulates that teachers can encourage deep learning by supporting student learning in a positive and encouraging atmosphere. ${ }^{9}$

\subsection{Performance goal theory:}

Students with a performance goal orientation are striving to perform better than others. Achieving success with little effort is perceived as a desirable goal. Because performance oriented or competitively oriented environments encourage an ability focus, they do not support the use of strategies that require sustained effort over time. ${ }^{10}$ It has been postulated that the tendency in UK higher education towards measurable outcomes in order to justify fee charging could encourage performance goal orientation. Tomlinson describes this as 'gaming on the part of students including approaches to assessment and jumping through whatever hoops they can to attain desired outcomes. ${ }^{11}$ Performance goal, sometimes called ego-involved, students try to outperform others and are more likely to do tasks they know they can do. ${ }^{12}$ 'Performance goal orientation has been associated with...an avoidance of challenging tasks; negative affect following failure, accompanied by a judgment that one lacks ability ... and use of superficial or short term learning strategies such as memorising and rehearsing. ${ }^{13}$ It leads to shallow learning.

There is some evidence that the substantial increase in university fees which came into effect in Autumn 2012 has led to a prevalence of performance goal orientation amongst students - called utilitarian and instrumental in this study. ${ }^{14}$ Tomlinson expresses concerns that the increasing

\footnotetext{
${ }^{9}$ Urdan and Schoenfelder, p. 335

${ }^{10}$ Garner cited in Ames, p265

${ }^{11}$ Michael Tomlinson, Conceptions of the value of higher education a measured market, Higher Education (2018) 75: 711-727, pp 721-722

${ }^{12}$ Eccles and Wigfield p.158

${ }^{13}$ Ames p.263

${ }^{14}$ Michael Tomlinson, Exploring the impact of policy changes on students' attitudes and approaches to learning in higher education.(undated) p.37
} 
marketisation of higher education is encouraging more students to think instrumentally about immediate economic goals ${ }^{15}$. He describes the performativity of the higher education sector - the idea that only what is measurable matters. This devalues less tangible outcomes which are, nevertheless, valuable to society. Less tangible outcomes can be private good or public good. One example of public good that he describes is 'the secondary effects of skilled graduates passing on knowledge within a workplace context, potentially enhancing the productive capacity amongst those who have not personally benefited from higher education. ${ }^{16}$ Another study has identified a correlation between the 'students as consumer' (SAC) and the consumerist attitude this engenders, and a performance goal approach to learning - although the terminology of 'grade goal' is used. ${ }^{17}$ It found a 'negative relationship between a consumer orientation and academic performance.' ${ }^{18}$

However, whilst increasing the price of degree level study has made students more conscious of the need to focus on outcomes, in particular in terms of employability, Tomlinson also found evidence that students have not completely abandoned other less tangible goals - 'dual and competing goals and values co-exist. ${ }^{19}$ He identifies a 'mixture of extrinsic economically-oriented goals and more academic, learner-centred goals'..$^{20}$

It seems counter intuitive that achievement goal orientation should, in the longer term actually lead to poor achievement in terms of results, but this is what the empirical research has shown. The focus on short term achievement is at the expense of the deeper learning and skills mastery which leads to more consistent and longer term achievement in learning. ${ }^{21}$

\subsection{A $2 \times 2$ achievement goal framework}

\footnotetext{
15 Michael Tomlinson 2018: 711-727

16 Tomlinson 2018, p.719

${ }^{17}$ Louise Bunce, Amy Baird and Sian E Jones, The student-as-consumer approach in higher education and its effects on academic performance, Studies in Higher Education, 2016, p.1962

${ }^{18}$ Bunce et al, p.1973

19 Tomlinson p.38

20 Tomlinson p.6

${ }^{21}$ Ames p. 262-263
} 
This dichotomy of mastery goal orientation and performance goal orientation has since been further developed to include another dimension by introducing achievement and avoidance strategies.

Performance goal orientation can be split into two sub categories '(a) wanting to demonstrate ability [ performance achievement approach]...and (b) wanting to avoid demonstrating a lack of ability [performance avoidance approach] ${ }^{22}$ This created a trichotomous achievement goal theory. The classic vision of a performance goal student was of someone who would adopt a failure avoidance pattern of learning. However, this theory postulates that some performance goal students are motivated to engage in performance achievement approach methods rather than performance avoidance methods. ${ }^{23}$ This theoretical model has since been applied in empirical research. ${ }^{24252627}$ This bifurcation model has now been extended to cover mastery goal orientation as well so that mastery acheivement goal describes the original concept of mastery goal students those motivated to improve their skills, understand their work and improve their competence, and is joined by a new category of mastery avoidance goals. This created a fourfold achievement goal theory: described as the $2 \times 2$ achievement goal framework. ${ }^{28}$ Whilst mastery achievement goal motivation is a desire to master particular skills, mastery avoidance can be described as trying to avoid not being competent in those skills e.g. 'striving to avoid misunderstanding or failing to learn course material, striving not to make an error in a business transaction, striving not to miss a free throw in a basketball game ${ }^{29}$ Hence the desire to master a skill morphs into the desire not to fail to master that skill.

\footnotetext{
${ }^{22}$ Julianne C Turner, Carol Midgley, Debra K Meyer, Margaret Gheen, Eric M Anderman and Yongjin Kang, 'The Classroom environment and students' reports of avoidance strategies in mathematics: a multi method study', Journal of Education Psychology, 2002, vol 94, no1 88-106, p.103

${ }^{23}$ Andrew J Elliot and Holly A McGregor, A 2 × 2 achievement goal framework, Journal of Personality and Social Psychology, 2001, Vol 80, no 3, p.501

${ }^{24}$ Elliot and McGregor, p.501

25 Turner et al

${ }^{26}$ Steven M Huff, Christopher T Stripling, Christopher Boyer and Carrie A Stephens, Investigating Factors that Influence Achievement Goal Orientation and Educational Practices in Undergraduate Agricultural Sciences and Natural Resource Students, NACTA Journal, December 2016, Vol 60(4), p.428 - 429

${ }^{27}$ Rachel M Korn and Andrew Elliot, The 2x2 Standpoints Model of Achievement Goals, Frontiers in Psychology, 2016 7:742

${ }^{28}$ Elliott and McGregor, pp. 501 - 519

${ }^{29}$ Elliot and McGregor, p.502
} 


\begin{tabular}{l|l|l} 
& Mastery goal orientation & Performance goal orientation \\
\hline Achievement strategy & $\begin{array}{l}\text { Desire to master particular } \\
\text { skills }\end{array}$ & $\begin{array}{l}\text { Wanting to demonstrate } \\
\text { ability }\end{array}$ \\
\hline Avoidance strategy & $\begin{array}{l}\text { Trying to avoid not being } \\
\text { competent in those skills }\end{array}$ & $\begin{array}{l}\text { Wanting to avoid } \\
\text { demonstrating a lack of ability }\end{array}$
\end{tabular}

Figure 1a $2 \times 2$ achievement goal framework

One example of an empirical study using this $2 \times 2$ achievement goal theory model was into students at an agricultural college in the United States. The study identified multiple reasons students engaged in academic tasks but found students who were, on the whole, more oriented to masteryapproach and less oriented towards mastery avoidance. It also recommended teaching strategies for improving students performance informed by this model. ${ }^{30}$

\section{Lecturers can influence students' achievement goal orientation.}

Given the importance of achievement strategy in improving students results, and the prevailing higher education environment in the UK which perceives the student as consumer, how can lecturers encourage positive behaviour and attitudes in students? Some researchers have identified that teachers can have an influence on students' engagement. ${ }^{31}$ Academic researchers identify two roles in teaching, the academic instructor, who is focussed on teaching academic skills and the socialiser who is more concerned with the students social-emotional needs and their behaviour. In their opinion the most effective teachers blend the two roles, in other words teaching academic skills has to be balanced with addressing emotional literacy: fostering the 'good citizen'32 They also identify differences between teachers who believe that ability is innate (entity view of intelligence) and those who believe that intelligence can be improved (incremental view). Teachers with an

\footnotetext{
${ }^{30}$ Huff et al

${ }^{31}$ Nick Zepke, Student engagement research in higher education: Questioning an academic orthodoxy, Teaching in Higher Education 19(6) pp 697 - 708, 2014

32 Eccles and Wigfield, pp. $167-169$ 
incremental view will tend to adopt a mastery goal orientation leading to students more concerned with mastering tasks, understanding the material and self-improvement. ${ }^{33}$ They state that students perception of caring teachers enhance their feelings of self-esteem. ${ }^{34}$ Other researchers too state that 'individuals achievement goals are content and context specific' ${ }^{35}$ ' $[\mathrm{B}]$ oth formal and informal experiences of higher education can significantly enhance student agency and build a variety of capitals, including personal and identity capital. ${ }^{\prime 36} \mathrm{~A}$ university degree only becomes meaningful if it embodies experiences and forms of learning that are empowering to individuals and enhances personal autonomy. ${ }^{37}$

\subsection{The social cognitive perspective}

Research on how lecturers influence student learning has more recently concentrated on the socialcognitive perspective. This postulates that beliefs about academic ability, expectation about outcomes of engaging in the task, goals for the task are influenced by social contextual factors. These include messages from the teacher about the difficulty of the task, perceived ability of classmates, information about the importance of the learning material etc. Motivation comes from the interaction between individuals within the social context of the class/ school. ${ }^{38} \mathrm{~A}$ combination of differential treatment by teachers, evaluative feedback and social comparisons with their peers affects students own competence related beliefs. ${ }^{39}$ Practices which can influence students to adopt mastery goal approaches include designing tasks that are varied and appeal to individual interests. Students should be given as much autonomy as possible and be able to actively participate in

\footnotetext{
${ }^{33}$ Eccles and Wigfield pp $162-163$

${ }^{34}$ Eccles and Wigfield p.165

${ }^{35}$ Soylu Meryerb Yilmaz, Nary G Zeleny, Ruomeng Zhao, Roger H Bruning, Michael S Dempsey and Douglas F Kaufmann, Secondary Students' Writing Achievement Goals: Assessing the Mediating Effects of Mastery and Performance Goals on Writing Self-Efficacy, Affect and Writing Achievement, Frontiers in Psychology, Vol8: 2017, p.1

36 Tomlinson 2018, p.723

37 Tomlinson 2018. p723

${ }^{38}$ Ames, Classrooms; Goals, Structures, and Student Motivation, Journal of Educational Psychology, 1992, Vol 84 , No $3261-271$

pp $264-266$

${ }^{39}$ Eccles and Wigfield p 155
} 
planning and making decisions. Grades should be communicated privately and not be displayed in public as this would encourage competition which then leads to a performance goal (or ego-goal) approach to learning. ${ }^{40}$ Some researchers talk about 'learned helplessness' advocating how this can be a reaction to facing tasks which are too difficult and being given feedback which emphasises that their failures are due to a lack of ability i.e. ability is innate and cannot be changed by effort. ${ }^{41}$ This demotivates the student, undermining any tendency towards mastery goal orientation.

Teachers are encouraged to shift their roles away from the lecturing controlling expert toward a more nurturing supportive facilitator that can provide appropriate levels of support, giving students opportunities to learn for themselves at their own pace. Students' perception of an emphasis on mastery in their learning environment has been positively correlated with their perception of caring, respectful teachers. ${ }^{42}$

\subsection{Social relationships and their influence on students' motivation.}

How do teacher and peer relationships in the classroom influence students' motivation? There is evidence that students will respond positively to teaching that is supportive and where they perceive that teachers care about them. ${ }^{43}$ Some research has shown that allocating students to sets by ability becomes a self-fulfilling prophecy. Those students in the lower ability streams feel less valued and doubt their own ability. Concentrating children with similar behavioural vulnerabilities magnifies the effect of those vulnerabilities leading, in one researched case, to increased aggression. ${ }^{44}$ Research into links between style of teaching and student achievement goal orientation found that 'teachers in high mastery-oriented classrooms spoke about learning as an active process, whereas those in low mastery-oriented classrooms endorsed a transmission model of learning ${ }^{\prime 45}$ Similarly the

\footnotetext{
${ }^{40}$ Fatma Kayan Fadelmula, Educational motivation and students' achievement goal orientation, Procedia Social and Behavioural Sciences, 2010, p861

${ }^{41}$ Eccles and Wigfield $\mathrm{p} 158$

42 Turner et al p.103

43 Urdan and Schoenfelder, , p.340

${ }^{44}$ Eccles and Wigfield pp.. 167 - 169

45 Turner, et al p.90
} 
use of controlling methods (sanctions, public feedback) has been correlated with having a negative effect on students, sometimes leading to an escalation of negative behaviour. ${ }^{46}$ In order to nurture students' motivation, leading them away from performance goal orientation and encouraging mastery goal approaches to learning a method of structuring that classroom discourse has been proposed which is described as 'scaffolding instruction' ${ }^{47}$

\section{Scaffolding instruction.}

Scaffolding instruction proposes initially giving a high level of support to allow students to make mistakes and learn from them in a perceived safe learning environment. This helps them develop the confidence to take academic risks later which facilitates meaningful engagement with the material and deeper learning. ${ }^{48} \mathrm{It}$ is the opposite of mechanical rote learning. The initial high level of support is gradually withdrawn as confidence develops and the students become more autonomous in their learning. This encourages deep learning and skills mastery. However, the level of support needs to be carefully judged as there is evidence that, where teachers offer excessive help, this can lower learners expectations of their own success. ${ }^{49}$ The US agricultural study mentioned earlier recommends that lecturers 'scaffold complex tasks or skills to allow students opportunities to build or support their academic efficacy. ${ }^{\prime 50}$ Once the skill has been mastered the scaffolding is no longer needed.

Scaffolding instruction involves constructive approaches to accepting mistakes and not criticising or humiliating the student. Humiliation or sarcasm will deter students from participating in the classroom. But feedback which attributes success to ability and effort and attributes failure to insufficient effort is likely to encourage a mastery goal approach in students. ${ }^{51}$ This article will concentrate on two ways to create scaffolding instruction:

\footnotetext{
${ }^{46}$ Eccles and Wigfield p.164

47 Urdan and Schoenfelder p.341

${ }^{48}$ Urdan and Schoenfelder pp340 - 341

${ }^{49}$ Eccles and Wigfield p.162

${ }^{50}$ Huff et al, p.429

${ }^{51}$ Eccles and Wigfield p.159
} 
1) Classroom social climate: this can be used to provide intrinsic support for learning by giving it value and fostering confidence.

2) Task: presenting a reasonable challenge which is not too difficult. Specific examples which have been used by the author to teach and assess legal problem solving will be discussed later and are included in this article.

\subsection{Classroom social climate: scaffolding instruction in the classroom environment.}

Supporting learning by giving it value and fostering confidence involves giving students positive feedback to their classroom contributions, never humiliating them. The word 'wrong' should not be used.

'If students perceive teachers as supporting their learning through what they say, the students may be less likely to adopt defensive measures such as avoidance strategies. Conversely if students perceive teacher discourse as non-supportive - as suggesting that they cannot or will not meet expectations - they may then adopt avoidance strategies. ${ }^{152}$ Academic research describes students who perceive that teachers have high expectations of them experiencing 'a greater sense of esteem and competence as learners' and achieving more. ${ }^{53}$. A study into the effects of the classroom environment on students' learning describes supportive discourse patterns that reflect scaffolding with an emphasis on learning, improvement, and understanding. The study stresses that these are expected to contribute to the perception of a mastery-focused goal structure and to lower the use of avoidance strategies. ${ }^{54}$ 'When teachers send messages that they will help students learn and students are able to assume responsibility for their increased competence then students should not fear appearing unable. ${ }^{.55}$ Therefore they should not be tempted to engage in avoidance strategies: strategies which are detrimental to learning. As

\footnotetext{
52 Turner et al p.90

53 Eccles and Wigfield p.,161

${ }^{54}$ Turner et al p.90

55 Turner et al p.90
} 
academics we should remember this basic principle, our expectations of our students do matter. They transmit to the students and affect their performance.

One study researched four different classrooms with four different teaching styles. The researchers identified two classes with low-avoidance high mastery goal patterns. In both of these classrooms the teachers engaged in motivational support and ensured that students understood what they were being taught. One teacher emphasised 'understanding and developing student independence as ...thinkers' and the other negotiated 'understanding and transferring responsibility to students when they had demonstrated mastery. ${ }^{56}$ Another common factor in both classrooms was the use of shared humour.

The two other classrooms were identified as high avoidance/low mastery classes. In one - a 'high demand for correctness [was coupled with] low support, both cognitive and motivational. ${ }^{57}$ In the other, although cognitive support was given, motivational support was very low. ${ }^{58}$ This empirical research clearly demonstrates that teachers' learning styles and the social atmosphere the teacher creates in the classroom have an effect on students' approach to learning.

The author attempts to facilitate students' learning by encouraging active participation in the classroom. When teaching the aim is to create an atmosphere where all students acquire sufficient self-confidence to participate fully in discussions in class. She believes that teachers can encourage deep learning by supporting student learning in a positive and encouraging atmosphere. ${ }^{59}$ Some studies have also postulated that using cooperative learning techniques, may reduce competitive thinking and increase the students orientation towards mastery learning. ${ }^{60}$ One review of the

\footnotetext{
${ }^{56}$ Turner et al p.98

57 Turner et al p98

58 Turner et al p.98

${ }^{59}$ Urdan and Schoenfelder, p. 335

${ }^{60}$ Huff et al, p.429
} 
evidence of the influence of the classroom environment on students' motivation advocates creating cooperative classrooms to improve learning. ${ }^{61}$ As students gain confidence and competence the support from the teacher can be reduced and the student internalises the methods and strategies needed for completing the work well. ${ }^{62}$ Scaffolding instruction thus implies giving more support for first year students and reducing the support in the second and third years.

The author uses the following teaching techniques in seminars to encourage cooperative learning. She makes extensive use of buzz groups, small groups of two or maximum three students discussing with each other. This fosters collaboration. Questions are then put to the group rather than to an individual. If a group is struggling to answer a particular questions than it is thrown open to the whole class by asking who can help? This fosters cooperative support amongst the students within the class as a whole .

\subsection{Scaffolding instruction and tasks: presenting a reasonable challenge which is not too difficult}

Tasks should be tailored to appropriate attention levels. The topics should be made meaningful to students by stressing the practical applications of subjects. Presenting students with tasks which are too difficult leads to giving up and demotivation: the very avoidance strategies which should not be encouraged. 'When the work is too difficult, motivation is diminished because students lack confidence, feel coerced into completing work that is too difficult and become overly concerned with failing, ${ }^{63}$ In tutorials this can involve questioning the students to break down the challenging material into manageable subsidiary issues and enabling them to form their own conclusions. ${ }^{64}$

\footnotetext{
${ }^{61}$ Eccles and Wigfield $\mathrm{p} 165$

62 Urdan and Schoenfelder p.341

63 Urdan and Schoenfelder, p339

${ }^{64}$ Urdan and Schoenfelder, p.341
} 
First year law students in particular are confronted with novel situations caused by the emphasis placed on skills which are relevant to legal practice: for example, answering legal problem questions. It can be difficult for law lecturers to understand just how intimidating it is for students faced with such novel assessments.

The author has used two different methods of supporting students to acquire the necessary skills to deal with legal problem questions in her own teaching. One method, which offers stronger support (or scaffolding), incorporates the IRAC (Issue, Rule, Application, Conclusion) framework for legal problem solving. This has been used with first year students of a university with a very diverse student body. Dividing up the questions in to the individual legal issues and posing them questions which reference to the IRAC framework serves two purposes. Firstly, dividing the problem questions into the component subsidiary legal issues makes it less intimidating and gives them a starting point for their legal research. Secondly it trains them to consistently use IRAC not only when solving legal problem questions, but also when writing their answers. The question is made easier, and a structure is provided for the written answer. See below for an example of a question subdivided using the IRAC structure.

\section{Roast bean problem - Version 1 - IRAC}

Edenbridge is about to celebrate 10 years of fair trade with a Fairtrade Fortnight, which is expected to attract high visitor numbers. "Roast Bean" therefore order twice their usual amount of coffee beans from Caffex coffee importers. Caffex lose the order and only deliver the normal amount.

1.a) State the specific legal issues that arise from the above facts.

b) State the legal rules which are relevant to the particular issue, including citing the relevant case(s).

c) Apply the legal principles to the facts of the problem.

It is too late for Roast Bean to order fair trade coffee from anywhere else.

2. a) State the specific legal issues that arise from the above facts.

b) State the legal rules which are relevant to the particular issue, including citing the relevant case(s).

c) Apply the legal principles to the facts of the problem.

They have to close halfway through Fairtrade Fortnight losing any further custom 
3. a) State the specific legal issues that arise from the above facts.

b) State the legal rules which are relevant to the particular issue, including citing the relevant case(s).

c) Apply the legal principles to the facts of the problem.

They also lose the opportunity to be considered for a special competition during Fairtrade Fortnight to find the best fair trade business in Edenbridge.

4. a) State the specific legal issues that arise from the above facts.

b) State the legal rules which are relevant to the particular issue, including citing the relevant case(s).

c) Apply the legal principles to the facts of the problem.

Kentish TV have a contract with Roast Bean to make a programme about Fairtrade Fortnight based around what happens in Roast Bean Café and are paying Roast Bean $£ 500$ per week for the use of their café as a base. They have to shut down in the second week and now have insufficient material to complete the programme.

5 a) State the specific legal issues that arise from the above facts.

b) State the legal rules which are relevant to the particular issue, including citing the relevant case(s).

c) Apply the legal principles to the facts of the problem.

6. What conclusions do you come to on these legal issues?

The second method, with slightly less scaffolding has been used to teach and assess second and third year business school students who only encounter legal problem questions in the single law module in their degree. This is therefore a novel skill for them too. This still sub-divides the question into its various legal issues but removes the IRAC framework as scaffolding. The students are still given support in how to attack the problem question but they are given less scaffolding support thus encouraging them to become more autonomous in how they answer the questions. This method can also be applied where students have had time to build up their confidence with the more supportive IRAC style questions. See below for an example using the same question as before.

Roast bean problem - Version 2 Roast Bean" is a small café in Edenbridge, the first fair trade town in England. Edenbridge is about to celebrate 10 years of fair trade with a Fairtrade Fortnight, which is expected to attract high visitor numbers. "Roast Bean" therefore order twice their usual amount of coffee beans from Caffex coffee importers.

Caffex lose the order and only deliver the normal amount. It is too late for Roast Bean to order fair trade coffee from anywhere else. They have to close halfway through Fairtrade Fortnight losing any 
further custom. They also lose the opportunity to be considered for a special competition during Fairtrade Fortnight to find the best fair trade business in Edenbridge.

a)What is the legal relevance of Caffex losing the order and delivering the normal amount?

b)Can Roast Bean claim for the loss of custom from closing halfway through Fairtrade Fortnight? If so why? If not why not?

c)Can Roast Bean claim for the loss of income from Kentish TV? Give legal reasons who or why not?

This approach can also be modified and used to break essay questions into more manageable tasks. Both methods should only be used to introduce students to new skills. Once the students have had an opportunity to acquire confidence the scaffolding should be removed. For example, these types of questions would not be considered appropriate for second and third year law students who should have moved beyond the need for this level of support. These types of question can also be used for assessment purposes at the appropriate level of study.

Students are more likely to engage in an activity if they perceive meaningful reasons for developing an understanding of the content of the activity, improving their skills, or gaining new skills. Task presentation should emphasise personal relevance and meaningfulness of the content. To some extent this is made easier by the subject matter of a law course. The case reports provide real life situations where it is clear that the law is relevant to people's everyday lives. Of course, many of the core cases used in standard textbooks are dated and it can be necessary to give a similar modern equivalent. However, there are many amazing stories in law reports giving scope for making the material relevant to the students' lives and making learning fun. One academic study recommends planning assignments that build upon each other and explicitly connecting assignments and tasks both to the students previous experience and to their future utility. ${ }^{65}$

The author runs a module on Commercial Law for Business at the Business School of Birkbeck College, University of London. Business school students only study a single law module, this means that legal problem solving is a novel skill which they are only confronted with in this particular

${ }^{65}$ Huff et al, p.429 
module. It is therefore hardly surprising that they struggle with this specific form of assessment. In the academic year 2016/2017 the legal problem questions were reformatted - both for the exams and for the tutorials. They were broken into a series of smaller more discrete questions using the second method shown above, to make it easier for non-law students to spot all the legal issues. Non law students are a different learning community to law students and need adjustments in both teaching and assessment to help them cope with this challenging material. After this adjustment was made the student results improved. The exam includes problem questions, the coursework does not, it is an essay question. Between 2015/16 and 2016/17, when the format of the problem questions was changed, the exam marks increased as follows: mean marks up by $12 \%$ and median marks by $12.5 \%$ as against an overall increase in the results by only $5.6 \%$ and $2.5 \%$ respectively. This demonstrates that the use of additional scaffolding of the problem questions had the desired defect of improving student results. This type of scaffolded question has also been used in foundation law modules as an introduction to legal problem solving for students who have never encountered legal problem questions before. Whilst it can be recommended for first year law modules there should be no need for this level of scaffolding in the second and third year of a law degree where students should have already acquired the self confidence to tackle legal problem questions.

\section{Conclusion}

Achievement goal theory provides a persuasive description of student motivation to learn and how the orientation of that motivation affects student learning. Achievement goal theory has divided motivation to learn into two categories: mastery goal approach, where students strive to master a skill, and performance (ego-centered) goal where students compare their performance with other students. These two categories have been further subdivided into achievement and avoidance strategies creating a $2 \times 2$ achievement goal theory. Of the four categories thus created, mastery achievement approach has been shown through empirical research to create the most desirable 
outcomes in terms of student learning: it encourages deep learning and mastery of the requisite skills.

Lecturers can encourage students to adopt mastery achievement approaches to learning through the use of scaffolding instruction. Scaffolding instruction initially provides a high level of support in order to develop self-confidence in students, gradually removing that support as students become confident autonomous learners. This is achieved in two different ways, through creating a supportive and encouraging class room social environment where learning is valued and through providing tasks which are at the appropriate level of difficulty presenting a reasonable challenge but not being so difficult that students struggle and are discouraged. The author provides examples from her own teaching which illustrate how she has implemented scaffolding instruction in her teaching and assessment practice. This includes examples of two different approaches to supporting how students learn the law specific skill of legal problem solving. These have been used both with first year law students and, with demonstrable success, with business school students. 